\title{
Cistoadenoma biliar como diagnóstico diferencial de hidatidosis hepática. Reporte de caso
}

\author{
Drs. César Muñoz $C^{(1,2)}$, Héctor Losada $M^{(1,2)}$, Óscar Tapia $E^{(1)}$, Andrés Troncoso $F^{(2)}$.
}

1. Hospital Hernán Henríquez Aravena. Temuco, Chile.

2. Universidad de La Frontera. Temuco, Chile.

\section{Biliary cystadenoma as differential diagnosis of hepatic hydatidosis. Case report}

\begin{abstract}
The biliary cystadenoma represents a rare cystic tumor that may compromise the liver and the extrahepatic bile duct. This tumor accounts for less than $5 \%$ of solitary non-parasitic cysts of the liver. Our aim is to report a clinical case as well as to discuss some issues concerning diagnosis and treatment options for this type of injuries.
\end{abstract}

Key words: Bile duct neoplasms, Cystadenoma, Cysts.

Resumen: El cistadenoma biliar es un tumor quístico infrecuente que puede comprometer el hígado y la vía biliar extrahepática. Este tumor representa menos del $5 \%$ de los quistes únicos no parasitarios del hígado. Nuestro objetivo es reportar un caso clínico y discutir algunos aspecto respecto al diagnóstico y tratamiento de este tipo de lesiones.

Palabras Clave: Cistoadenoma, Neoplasia de conductos biliares, Quistes.

Muñoz C y cols. Cistoadenoma biliar como diagnóstico diferencial de hidatidosis hepática. Reporte de caso. Rev Chil Radiol 2011; 17(4): 179-182.

Correspondencia: Dr. Héctor Losada M. / hflosadahpb@gmail.com

Trabajo recibido el 16 de agosto de 2011, aceptado para publicación el 09 de octubre de 2011.

\section{Introducción}

El cistoadenoma biliar (CAB) es un tumor quístico, benigno y no parasitario que puede comprometer el parénquima hepático o las vías biliares extrahepáticas. Su presentación es infrecuente, constituyendo menos del $5 \%$ de los tumores quísticos del hígado ${ }^{(1)}$. Su localización más habitual es a nivel hepático (80-85\%), seguido por los conductos biliares extrahepáticos y la vesícula biliar ${ }^{(2-6)}$.

Es importante diferenciar el CAB de otras lesiones quísticas no parasitarias del hígado y las vías biliares, dado el potencial de malignización de este tipo de tumores ${ }^{(1,7)}$.

La etiología del CAB es desconocida, y en la actualidad, se asume que este tipo de lesiones podría originarse a partir de un conducto biliar congénitamente aberrante o directamente a partir de una célula madre (stem cell) primitiva hepatobiliar ${ }^{(2,8,9)}$.

El CAB puede ser subdividido histológicamente en dos subtipos, basado en la presencia o ausencia de estroma mesenquimático ${ }^{(8,10)}$.

Nuestro objetivo es reportar un caso clínico y discutir algunos aspectos respecto al diagnóstico y tratamiento de este tipo de lesiones.

\section{Caso clínico}

Paciente de 41 años, género femenino y sin antecedentes mórbidos de importancias, consulta en policlínico de cirugía por cuadro de un mes de evolución caracterizado por dolor sordo en hipocondrio derecho e irradiado al dorso asociado a náuseas sin otros síntomas. Al examen físico destaca dolor a la palpación profunda del hipocondrio derecho y epigastrio. Los exámenes de laboratorio se encuentran dentro de parámetros normales. Una ecografía abdominal y tomografía computada de abdomen con contraste, evidencian una formación quística, con tabiques en su interior, que compromete el lóbulo hepático derecho y presenta una dilatación quística asociada del conducto hepático derecho (Figuras 1, 2 y 3). Ante los hallazgos imaginológicos, y con la sospecha diagnóstica de una hidatidosis hepática complicada, se decide hospitalización para resolución quirúrgica.

En el intraoperatorio se encuentra un gran quiste 


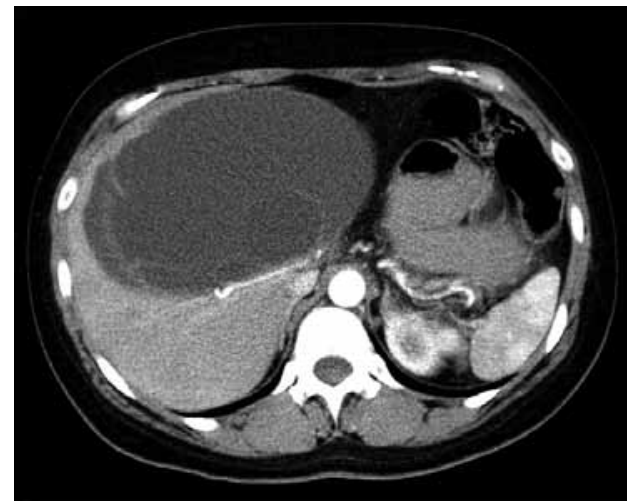

Figura 1. Tomografía computada abdominal con contraste endovenoso en fase arterial que evidencia lesión quística con finos septos en el lóbulo hepático derecho.

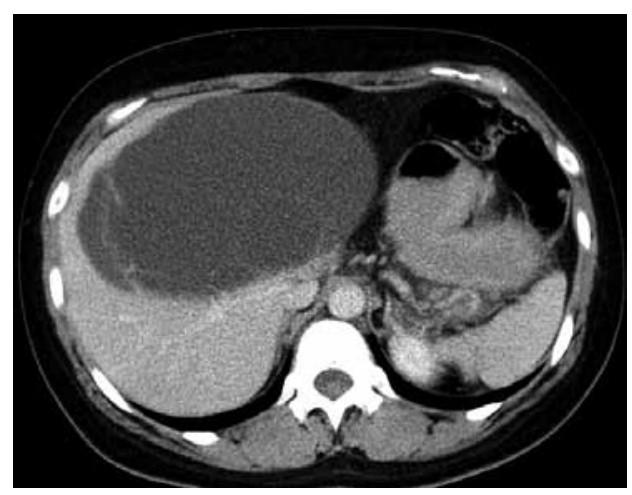

Figura 2. Tomografía computada abdominal con contraste endovenoso en fase venosa que evidencia lesión quística con finos septos en el lóbulo hepático derecho.

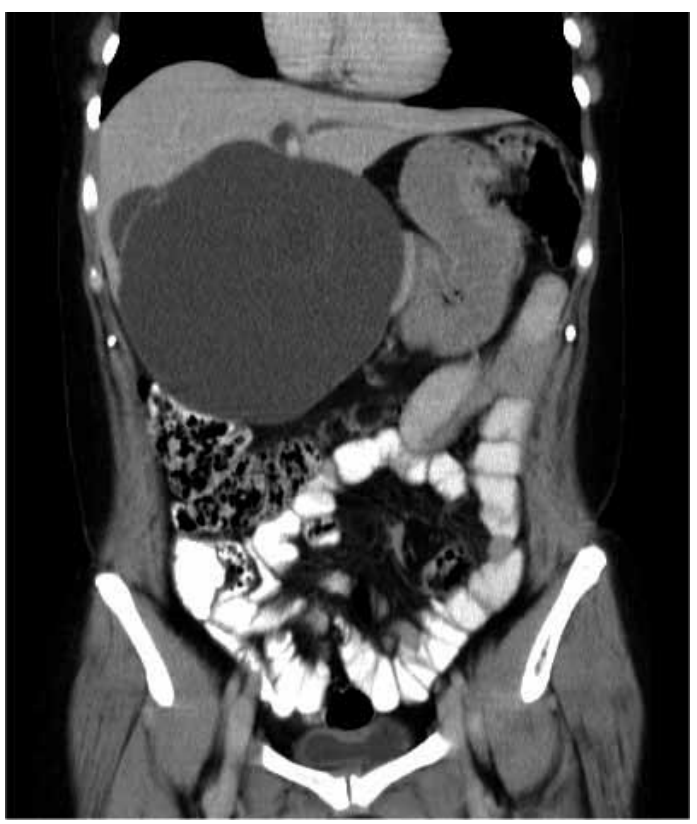

Figura 3. Tomografía abdominal con contraste endovenoso en reformateo coronal que evidencia lesión quística del lóbulo hepático derecho. hepático de aproximadamente $20 \mathrm{~cm}$ de diámetro, a tensión, de paredes finas con líquido hemático y bilioso en su interior. Dentro del quiste mayor, existen 2 quistes menores de similar aspecto, además se observa salida de bilis del interior del quiste mayor. Biopsia contemporánea señala quiste de tipo inflamatorio. Se realiza quistectomía subtotal y reparación de la dilatación del conducto hepático derecho, coledocotomía supraduodenal, colangiografía intraoperatoria y coledocostomía con sonda Kehr. La paciente evoluciona sin complicaciones postoperatorias y es dada de alta hospitalaria con control en el policlínico de la especialidad.

En control postoperatoria ambulatorio se evalúa estudio histopatológico diferido de la pieza quirúrgica que informa cistoadenoma mucoso con estroma ovárico (Figuras 4 y 5).

Se evalúa el caso y se decide reintervención para resección completa de la lesión dado el potencial neoplásico de este tipo de tumores quísticos. La paciente rechaza la propuesta de reintervención, y se decide control con imágenes cada 3 meses.

Aproximadamente a los 2 meses de postoperatorio, consulta en Servicio de Urgencias por cuadro de 3 días de evolución caracterizado por dolor abdominal en hipocondrio derecho, fiebre y sensación nauseosa. Al examen físico destaca abdomen blando y depresible con dolor a la palpación profunda en hipocondrio derecho. La coledocostomía supraduodenal está permeable. Se realiza una nueva tomografía computada que evidencia lesión quística de aproximadamente 4.7 cm de diámetro en el segmento IV del hígado, tabicado y sin líquido libre intraabdominal (Figuras 6, 7 y 8). Se decide hospitalización para resolución quirúrgica propuesta con anterioridad. En el intraoperatorio se encuentra lesión quística próximo a la vía biliar principal con compromiso del parénquima hepático del lóbulo hepático derecho y el segmento IV. Se realiza hepatectomía no anatómica, resección de vía biliar extrahepática y hepaticoyeyunoanastomosis en $Y$ de Roux. La paciente evoluciona sin complicaciones en el postoperatorio y es dada de alta al 6ํ́a día postoperatorio.

En controles postoperatorios realizados en el policlínico de la especialidad la paciente evoluciona asintomática y sin evidencia de recidiva.

\section{Discusión}

El CAB es un tumor quístico infrecuente, cuya característica más relevante es su potencial de malignización.

Al igual que en el caso clínico presentado, el diagnóstico habitualmente se realiza en un paciente de género femenino alrededor de la $5^{\text {a }}$ década de la vida $^{(1-3,5,6)}$. El motivo de consulta más frecuente es el aumento de volumen en hipocondrio derecho o masa palpable ${ }^{(11)}$ asociado a dolor abdominal sostenido e inespecífico ${ }^{(4,5,12)}$, junto a ellos pueden estar presentes 


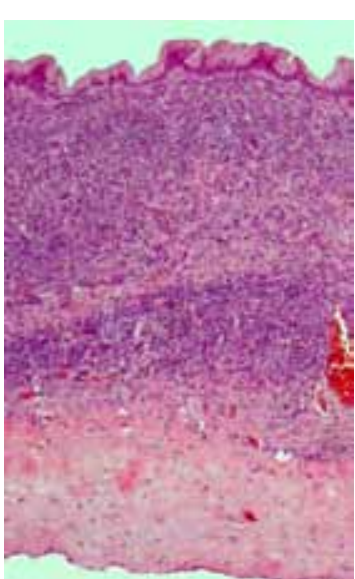

Figura 4. (HematoxilinaEosina 100x) Pared de quiste hepático revestido por epitelio columnar normotípico con estroma subepitelial denso compuesto por células fusiformes y ovales sin atipías citológicas de tipo ovárico compatible con cistoadenoma biliar.

Figura 5. (HematoxilinaEosina 400x) Pared de quiste hepático revestido por epitelio columnar normotípico con estroma subepitelial denso compuesto por células fusiformes y ovales sin atipías citológicas de tipo ovárico compatible con cistoadenoma biliar.

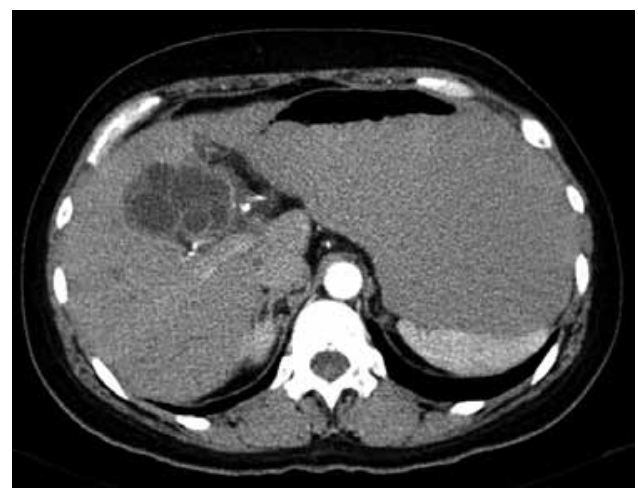

Figura 6. Tomografía abdominal con contraste en fase arterial que evidencia lesión quística septada recidivada del lóbulo hepático derecho.

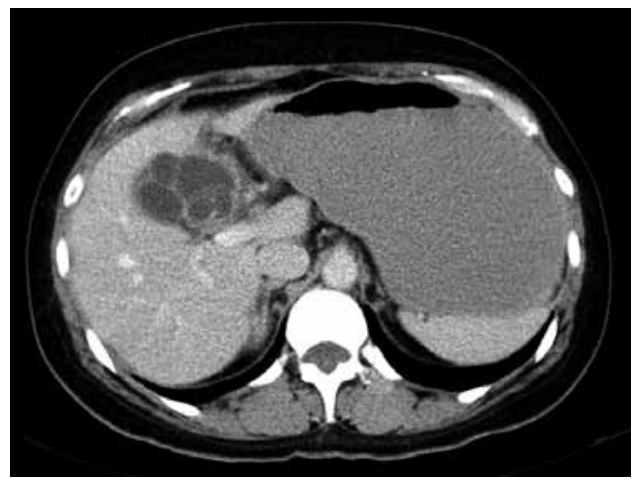

Figura 7. Tomografía abdominal con contraste endovenoso en fase venosa que evidencia lesión quística septada recidivada del lóbulo hepático derecho.

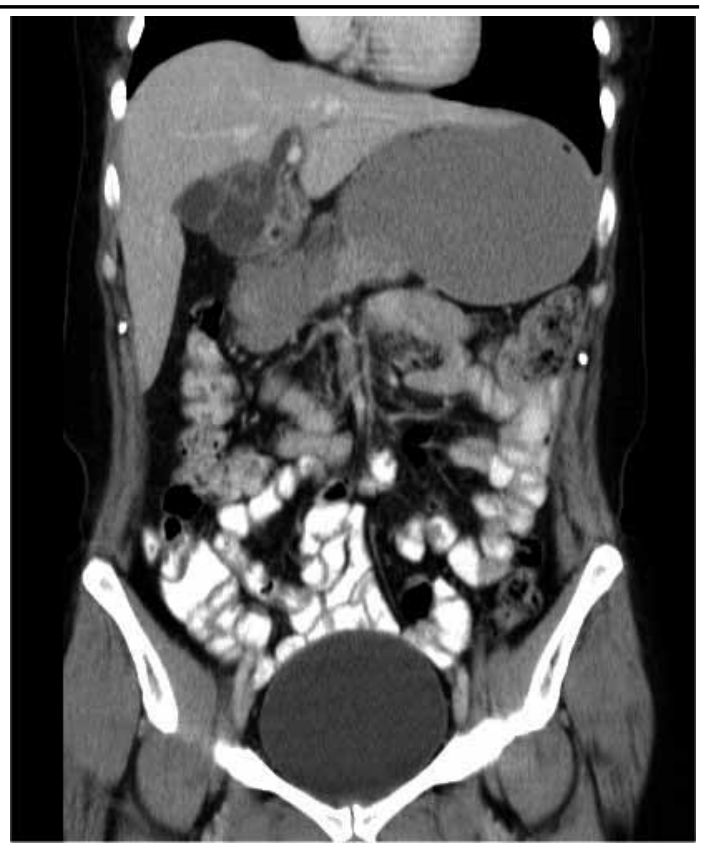

Figura 8. Tomografía abdominal con contraste endovenoso en reformateo coronal que evidencia lesión quística recidivada del lóbulo hepático derecho.

otros síntomas y signos tales como: ictericia ${ }^{(6)}$, oclusión intestinal, náuseas y vómitos, pérdida de peso o ascitis; y en una menor proporción los síntomas derivan de las complicaciones asociadas a rotura 0 hemorragia intraquística.

El laboratorio suele ser de poca ayuda en el diagnóstico, dado que la mayoría de los pacientes no presenta alteraciones en el hemograma o el perfil hepático. Se ha reportado la elevación del CA 19-9 (carbohydrate antigen 19-9) al momento del diagnóstico con un descenso a valores normales tras la cirugía resectiva, sin embargo, este hallazgo no es una situación habitual ${ }^{(13)}$.

El estudio imaginológico es el pilar fundamental del diagnóstico ${ }^{(14,15)}$, ya que recurriendo a las diferentes herramientas y métodos de estudio para una tumoración hepática el diagnóstico puede ser bastante preciso en la actualidad. La ultrasonografía abdominal es un examen útil como estudio inicial donde es posible reconocer una lesión quística anecogénica, bien definida y de pared delgada no calcificada con septos o tabiques internos altamente ecogénicos; en ocasiones es posible visualizar dilatación de la vía biliar intrahepática o extrahepática. La tomografía computada abdominal con contraste puede evidenciar una lesión bien definida con captación de contraste en la pared o en los septos internos, donde la presencia de calcificaciones en la pared de los septos sugiere el diagnóstico de un cistoadenocarcinoma. La resonancia magnética es de utilidad en señales T1 y T2 donde la lesión quística puede variar de intensidad dependiendo del contenido de proteínas o la presencia de hemorragia. La asociación de la colangiorresonancia 
puede aumentar la utilidad de este examen al proporcionar mayor información respecto a la vía biliar intra y extrahepática. Los hallazgos sugerentes de malignización de este tipo de lesiones son el engrosamiento irregular de la pared, los nódulos murales o proyecciones papilares de la pared ${ }^{(15)}$.

El diagnóstico diferencial del CAB se realiza con otras lesiones quísticas hepáticas como los quistes simples, hematomas intraparenquimatosos, abscesos hepáticos, quistes post-traumáticos, entre otros; y no es inhabitual que este tipo de lesiones sea inicialmente diagnosticada como hidatidosis hepática debido a sus similares características en los estudio imaginológicos preoperatorios ${ }^{(12,16)}$, situación que en este caso en particular, se ve fundamentada en la alta prevalencia de hidatidosis en nuestra población. El diagnóstico definitivo debe realizarse mediante un estudio histopatológico, por tanto, la indicación quirúrgica para este tipo de lesiones debe plantearse ante la sospecha diagnóstica de los estudios imaginológicos ${ }^{(1,2,5,7)}$.

Como se ha señalado anteriormente, el CAB posee características que justifican una conducta quirúrgica ante la sospecha diagnóstica mediante estudios imaginológicos. En este sentido, se recomienda una resección quirúrgica completa de la lesión, ya sea realizando una hepatectomía anatómica, hepatectomía no anatómica o quistectomía total ${ }^{(17)}$. La recomendación para una resección radical del CAB se fundamenta principalmente en dos situaciones. La primera, es que en resecciones incompletas de este tipo de lesiones se han reportado recurrencias ${ }^{(2,10,18)}$, situación que también ocurrió en nuestro caso, donde la biopsia contemporánea no justificaba una resección radical y la paciente rechazó la cirugía radical en una primera instancia. La segunda razón para recomendar una resección radical del CAB es la extirpación total del tejido con un conocido potencial de malignización ${ }^{(7,19)}$, donde las técnicas más conservadoras se han reportado con progresión a la malignización.

Finalmente, en los casos en los cuales se confirma una comunicación quistobiliar, el tratamiento de esta dependerá tanto de la ubicación como del tamaño del conducto biliar comprometido, pudiendo ir desde la simple sutura de la comunicación biliar hasta la resección hepática o de vía biliar principal con hepaticoyeyunoanastomosis en Y de Roux.

\section{Bibliografía}

1. Akwari OE, Tucker A, Seigler HF, Itani KM. Hepatobiliary cystadenoma with mesenchymal stroma. Ann Surg. 1990; 211(1): 18-27.

2. Ishak KG, Willis GW, Cummins SD, Bullock AA. Biliary cystadenoma and cystadenocarcinoma: report of 14 cases and review of the literature. Cancer. 1977; 38: 322-338.

3. Devaney K, Goodman ZD, Ishak KG. Hepatobiliary cystadenoma and cystadenocarcinoma. A light microscopic and immunohistochemical study of 70 patients. Am J Surg Pathol 1994; 18(11): 1078-1091.

4. Oh TH, Kim MH, Lee SK, Seo DW, Lee SS, Kim EY, et al. Thirteen cases of intrahepatic biliary cystadenoma and cystadenocarcinoma: a single center experience. Korean J Gastroenterol 2006; 47(5): 379-385.

5. Lee JH, Lee KG, Park HK, Lee KS. Biliary cystadenoma and cystadenocarcinoma of the liver: 10 cases of a single center experience. Hepatogastroenterology. 2009; 56 (91-92): 844-849.

6. Davies W, Chow M, Nagorney D. Extrahepatic biliary cystadenomas and cystadenocarcinoma. Report of seven cases and review of the literature. Ann Surg 1995; 222(5): 619-625.

7. Del Poggio P, Jamoletti C, Forloni B, De Benedictis R, Mattiello M, Corti D, et al. Malignant transformation of biliary cystadenoma: a difficult diagnosis. Dig Dis Sci 2000; 32(8): 733-736.

8. Wheeler DA, Edmondson HA. Cystadenoma with mesenchymal stroma (CMS) in the liver and bile ducts. A clinicopathologic study of 17 cases, 4 with malignant change. Cancer 1985; 56(6): 1434-1445.

9. Vogt D, Henderson J, Chmielewski E. Cystadenoma and Cystadenocarcinoma of the Liver: A Single Center Experience. J Am Coll Surg 2005; 200(5): 727-733.

10. Manouras A, Markogiannakis H, Lagoudianakis E, Katergiannakis V. Biliary cystadenoma with mesenchymal stroma: Report a case and review of the literature. World J Gastroenterol. 2006; 12(37): 6062-6069.

11. Kim HG. Biliary cystic neoplasm: biliary cystadenoma and biliary cystadenocarcinoma. Korean J Gastroenterol 2006; 47(1): 5-14.

12. Mantke R, Ridwelski K, Röcken C, Pross M, Schulz HU, Lippert H. Hepatobiliary cystadenoma. Chirurg 2001; 72(3): 277-280.

13. Tsepelaki A, Kirkilesis I, Katsiva V, Triantafillidis JK, Vagianos C. Biliary Ciystadenoma of the Liver: Case report and systematic review of the literature. Annals of Gastroenterology 2009; 22(4): 278-283.

14. Teoh AY, Ng SS, Lee KF, Lai PB. Biliary cystadeno$\mathrm{ma}$ and other complicated cystic lesions of the liver: diagnostic and therapeutic challenges. W J Surg 2006; 30(8): 1560-1566.

15. Mortele KJ, Ros PR. Cystic focal liver lesions in the adult: differential CT and MR imaging features. Radiographics 2001; 21(4): 895-910.

16. Yu J, Wang Y, Yu X, Liang P. Hepatobiliary mucinous cystadenoma and cystadenocarcinoma: report of six cases and review of the literature. Hepato-gastroenterology 2010; 57(99-100): 451-455.

17. Wu JM, Wu YM, Ho MC, Hu RH, Lee PH. Surgical treatment of biliary cystadenomas. Int Surg 2008; 93(6): 373-376.

18. Dixon E, Sutherland F, Mitchell P, McKinnon G, Nayak V. Cystadenomas of the liver: a spectrum of disease. Can J Surg. 2001; 44(5): 371-376.

19. Fukunaga $\mathrm{N}$, Ishikawa $M$, Ishikura $\mathrm{H}$, Ichimori T, Kimura S, Sakata A, et al. Hepatobiliary cystadenoma exhibiting morphologic changes from simple hepatic cyst shown by 11-year follow up imagings. World J Surg Oncol. 2008; 6: 129-135. 